\title{
Nanofiltration in Transforming Surface Water into Healthy Water: Comparison with Reverse Osmosis
}

\author{
L. D. Naidu, ${ }^{1}$ S. Saravanan, ${ }^{1}$ M. Chidambaram, ${ }^{2}$ Mukesh Goel, ${ }^{3}$ \\ Ashutosh Das, ${ }^{3}$ and J. Sarat Chandra Babu ${ }^{1}$ \\ ${ }^{1}$ Department of Chemical Engineering, National Institute of Technology, Tiruchirappalli 15, India \\ ${ }^{2}$ Department of Chemical Engineering, Indian Institute of Technology Madras, Chennai, India \\ ${ }^{3}$ Center for Environmental Engineering, PRIST University, Thanjavur, India
}

Correspondence should be addressed to L. D. Naidu; ldnaidu@gmail.com

Received 7 April 2015; Revised 12 May 2015; Accepted 18 May 2015

Academic Editor: Stefan I. Voicu

Copyright (C) 2015 L. D. Naidu et al. This is an open access article distributed under the Creative Commons Attribution License, which permits unrestricted use, distribution, and reproduction in any medium, provided the original work is properly cited.

\begin{abstract}
The natural surface water, especially available through rivers, is the main source of healthy water for the living beings throughout the world from ancient days as it consists of all essential minerals. With the advent of industrialization, gradually even the most prominent rivers have been polluted in all parts of the world. Although there are lots of technologies, nanofiltration (NF) has been chosen to transform river water into healthy water due to its unique advantages of retaining optimum TDS (with essential minerals required for human body), consuming of lower energy, and no usage of any chemicals. The prominent parameters of surface water and macro/microminerals of treated water have been analyzed. It is shown that NF is better in producing healthy water with high flux by consuming low energy.
\end{abstract}

\section{Introduction}

In early days of industrialization, the artificially produced demineralized or distilled or deionized or reverse osmosis water had extensive industrial uses rather than domestic applications [1]. It was clear from the very beginning that desalinated or demineralized water must be enriched with some minerals such as calcium carbonate or limestone to make it suitable as drinking water. This will also improve the taste $[2,3]$.

The intake of our daily exclusive drinking water of 1.53 liters should contain some of the above minerals, in such a way that the TDS should be $100-500 \mathrm{ppm}$ (healthy water) to ensure good health. The optimum TDS has been decided on the basis of good organoleptic characteristics, reduced corrosive nature and thirst-quenching properties of water [4-6]. Remineralization alone could not provide perfect composition of minerals for drinking water [7-9]. So, instead of demineralizing and remineralizing, it is better to come up with robust new methods of purifying water at lower cost with less energy and at the same time minimizing the usage of chemicals and the impact on the environment. One of such methods in recent times is nanofiltration (NF) for transforming surface water into healthy water [10-12]. NF is the newly developed pressure-driven membrane process for liquid-phase separations and has substituted reverse osmosis (RO) in several applications, owing to greater flux and lesser energy utilization rates. It is in fact termed as future technology for drinking water in 21st century. This work was taken up to show the effectiveness of NF in providing the optimum TDS $(100-500 \mathrm{ppm})$ in the permeate water as per the standards of WHO.

The results will also be compared with RO filtration. $\mathrm{RO}$ is based upon the fundamental pursuit for balance and has huge application in drinking water preparation, especially from salty seawater.

\section{Materials and Methods}

2.1. NF and RO Membrane. The nanofiltration and thin film composite (TFC) polyamide reverse osmosis membranes in 
TABLE 1: Membranes' characteristics.

\begin{tabular}{|c|c|}
\hline Manufacturer & Permionics Pvt. Ltd., Vadodara, India \\
\hline Membrane type & Thin film composite (TFC) polyamide \\
\hline Configuration & Spiral wound \\
\hline Dimensions & $\begin{array}{l}\text { Length of } 40 \text { inches, diameter of } 2.4 \\
\text { inches, and an effective area of } 2.5 \mathrm{~m}^{2}\end{array}$ \\
\hline Pure water flux & $\begin{array}{l}90 \mathrm{~L} /\left(\mathrm{h} \cdot \mathrm{m}^{2}\right) \text { at } 55.2 \text { bars of feed } \\
\text { pressure and } 25^{\circ} \mathrm{C} \text { temperature }\end{array}$ \\
\hline $\mathrm{NaCl}$ salt rejection & $\begin{array}{l}99.4 \% \text { for } 32,000 \mathrm{mg} / \mathrm{L} \text { feed } \\
\text { concentration at the } \mathrm{pH} \text { range of } 2 \text { to } 11\end{array}$ \\
\hline $\begin{array}{l}\text { Recommended applied } \\
\text { pressure }\end{array}$ & $3-14$ bars \\
\hline $\begin{array}{l}\text { Maximum applied } \\
\text { pressure }\end{array}$ & 41 bars \\
\hline $\begin{array}{l}\text { Recommended applied } \\
\text { temperature }\end{array}$ & $2-45^{\circ} \mathrm{C}$ \\
\hline
\end{tabular}

TABLE 2: Characteristics of Cauvery river water collected from infiltration gallery.

\begin{tabular}{lc}
\hline Parameters & Respective values \\
\hline $\mathrm{pH}$ & 7.22 \\
Turbidity & 0 \\
Chlorides & $130 \mathrm{mg} / \mathrm{lit}$ \\
Total hardness & $220 \mathrm{mg} / \mathrm{lit}$ \\
Phosphates & $9.43 \mathrm{mg} / \mathrm{lit}$ \\
Nitrates & $13.43 \mathrm{mg} / \mathrm{lit}$ \\
Sulphates & $25 \mathrm{mg} / \mathrm{lit}$ \\
Total dissolved solids & $830 \mathrm{mg} / \mathrm{lit}$ \\
\hline
\end{tabular}

a spiral wound configuration were procured from Permionics Pvt. Ltd., Vadodara, India. The detailed description of the membrane is presented in Table 1. Tetrasodium-EDTA, hydrochloric acid, and sodium bisulfate were used for membrane cleaning and were supplied by Precision scientific Ltd., Tiruchirappalli, India.

2.2. Surface Water Characteristics. Surface water was procured from the nearby legendary Cauvery river, one of the prominent rivers in south India. In Table 2, the characteristic of the raw surface water is given.

2.3. Nanofiltration Pilot Plant System Description. The front view and the schematic representation of the membrane pilot system are shown in Figures 1 and 2, respectively. It consists of mainly spiral wound membrane module, incorporating, thin film composite nanofiltration (TFC-NF) membrane with an inlet pressure of 10 bars for the process of nanofiltration, inside the fiber-reinforced plastic (FRP) cylindrical pressure vessels with the dimensions of $2.5^{\prime \prime}$ diameter $\times 21^{\prime \prime}$ length (the size of each of the modules). A feed tank of $25 \mathrm{~L}$ capacity (SS316) was used for storage and supply of feed to the nanofiltration module. A high pressure pump capable of maintaining a pressure of 100 bars was installed for transporting the feed liquid. A 2 HP single-phase motor runs the respective pump. A restricting needle valve was provided at the concentrate

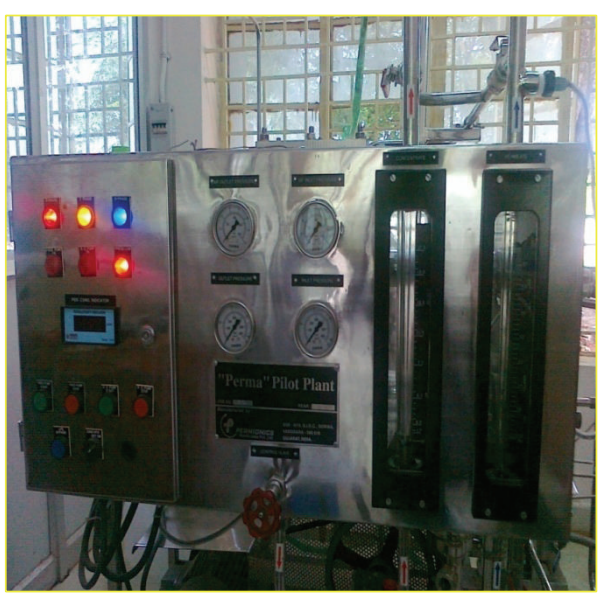

FIgURE 1: Front view of the NF and RO membrane process pilot plant.

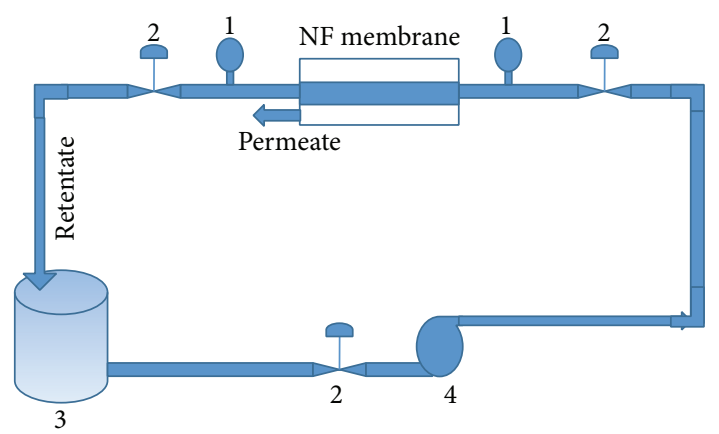
(1) Pressure indicator
(3) Storage tank
(2) Valve
(4) Pump

FIGURE 2: Schematic representation of the nanofiltration (NF) membrane pilot plant.

outlet, to pressurize the feed liquid to the desired value and the respective pressure indicated by a provided pressure gauge. Permeate and concentrate flow rates were measured by Rota meters. All the accessories were connected by $0.5^{\prime \prime}$ outer diameter stainless steel-316 piping in high pressure region, whereas low pressure outlets were made of PVC braided tubing.

2.4. Experimental Procedure and Sampling. Twenty-five liters of the feed was poured into the feed tank after thoroughly cleaning the membrane system and then wetted with the deionized water. A high pressure pump was employed to transport the feed to spiral wound membrane module. The retentate flow rate was maintained constant $(10 \mathrm{~L} / \mathrm{min})$ throughout the experimental runs to ensure identical hydrodynamic conditions inside the membrane module. Feed pressure was varied from 0 to 7 bars by keeping the feed TDS concentration constant. Flux was measured by collecting permeate in a measuring jar for a period of 2-3 min. About $300-$ $400 \mathrm{~mL}$ of permeate was collected for each pressure increase for a thorough analysis. Experiments were repeated twice 
with every feed sample for ensuring reproducibility of the permeate characteristics.

2.5. Analytical Methods. The feed and permeate of the nanofiltration processes were analyzed for TDS by TDS scan meter, chlorides were analyzed by titration method, $\mathrm{pH}$ was analyzed by digital $\mathrm{pH}$ meter, and TOC was analyzed by TOC analyzer. The feed water conductivity measured by conductivity meter and the permeate conductivity had been measured by online instrumentation. Nitrate, phosphate, and sulphate presented in the water samples were analyzed with DR 890 colorimeter (Hach, USA). Before testing any water samples, $10 \mathrm{~mL}$ of distilled water is taken in the colorimeter and tested for its zero value.

2.6. Flux and Percent Rejection. The percent rejection (\%R) of TDS can be calculated as given by Rautenbach and Albrecht [13]:

$$
\% R=\%\left(1-\frac{C_{p}}{C_{f}}\right) \times 100
$$

where $C_{f}$ and $C_{p}$ are the concentrations of a TDS (ppm) or particular component in the feed and permeate. The water flux $(J)$ (in $\left.\mathrm{L} /\left(\mathrm{m}^{2} \mathrm{~h}\right)\right)$ can be calculated as

$$
J(\mathrm{Lmh})=\frac{V}{A \times t},
$$

where $V$ is the volume of permeate collected $(\mathrm{L}), A$ is the membrane area $\left(\mathrm{m}^{2}\right)$, and $t$ is time $(\mathrm{h})$.

2.7. Power Consumption. Power consumption is a major factor in membrane separation process. Power consumption is calculated as shown below:

$$
P=\frac{Q \cdot p}{\eta},
$$

where $P$ is power consumed by feed pump or high pressure pump, $\mathrm{kW}, \mathrm{Q}$ is flow rate of permeate or retentate, $\mathrm{m}^{3} / \mathrm{sec}, p$ is pressure applied within the spiral wound module, $\mathrm{kPa}$, and $\eta$ is efficiency of the pump.

\section{Results and Discussion}

Membrane performance will be influenced by the variation of the feed pressure and percent rejection of TDS, chlorides of the surface water $[14,15]$. Moreover, the permeate TOC has been observed with the variation of pressure as it is very important parameter for surface water evaluation. Permeate flux, percent rejection of TDS and chlorides, and power consumption were compared for NF and RO membrane.

3.1. Effect of Pressure on Permeate Flux. Figure 3 shows the effects of applied pressure on permeate and concentrate fluxes as the pressure increases. The permeate flux increases linearly with increase of applied pressure which suggests that there may be negligible concentration polarization. As expected the concentrate flux is reduced as the pressure is increased.

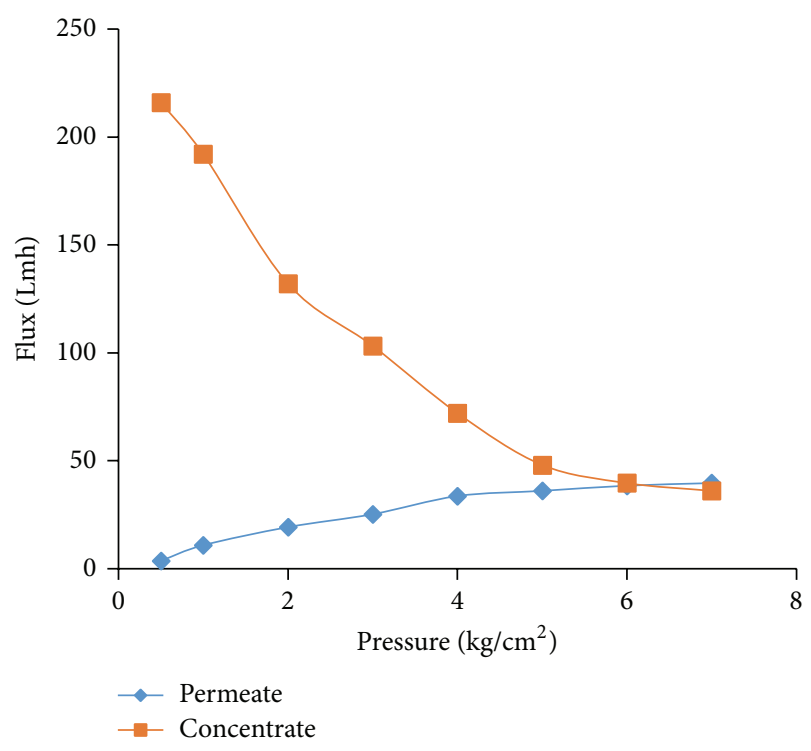

FIGURE 3: Fluxes of permeate and concentrate versus process pressure for nanofiltration.

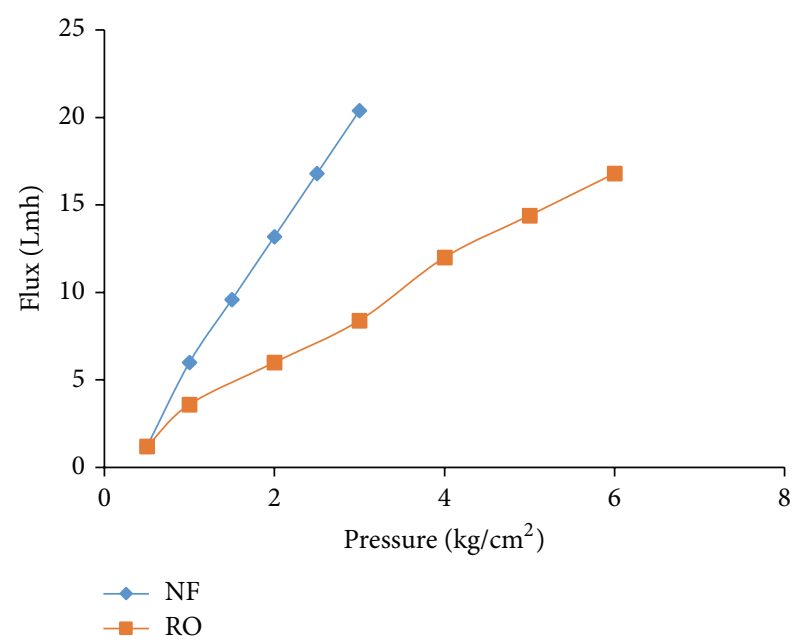

FIGURE 4: Comparing permeate flux as a function of pressure between NF and RO.

This indicated that the performance of membrane module is good. The permeate flux for both RO and NF is compared in Figure 4. In both cases, the permeate flux increases linearly with increase of applied pressure which suggests that there may be negligible concentration polarization for RO membrane as well. However, it can be observed that permeate flux obtained was more in case of NF. For the same pressure (3 bars), 20.4 Lmh of permeate flux was obtained during NF process whereas RO could facilitate only $8.4 \mathrm{Lmh}$. This is because of the small pore size of RO membranes, consequently yielding a higher pressure drop.

3.2. TOC Rejections by Membrane. The surface water TOC data is presented in Figure 5. The permeate TOC reduced from $653 \mathrm{mg} / \mathrm{L}$ to $267 \mathrm{mg} / \mathrm{L}$ indicating a high removal of 


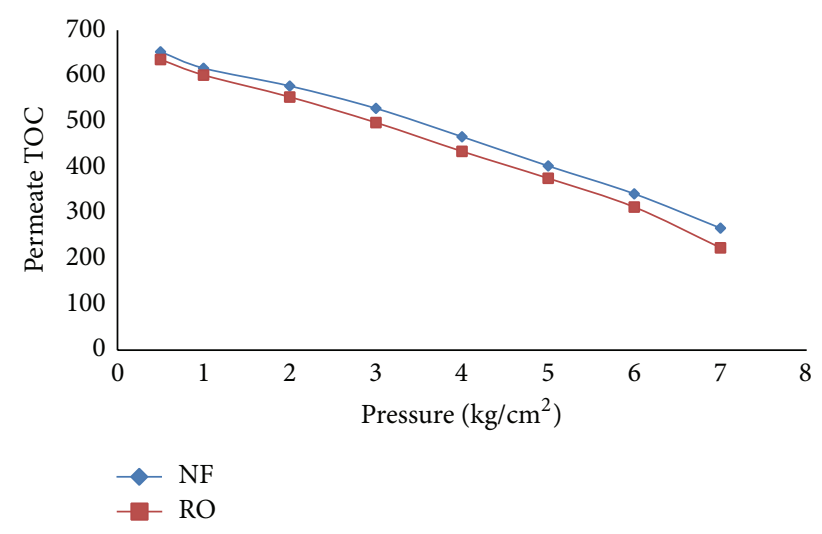

Figure 5: Comparing permeate total organic carbon (TOC) as a function of pressure between NF and RO.

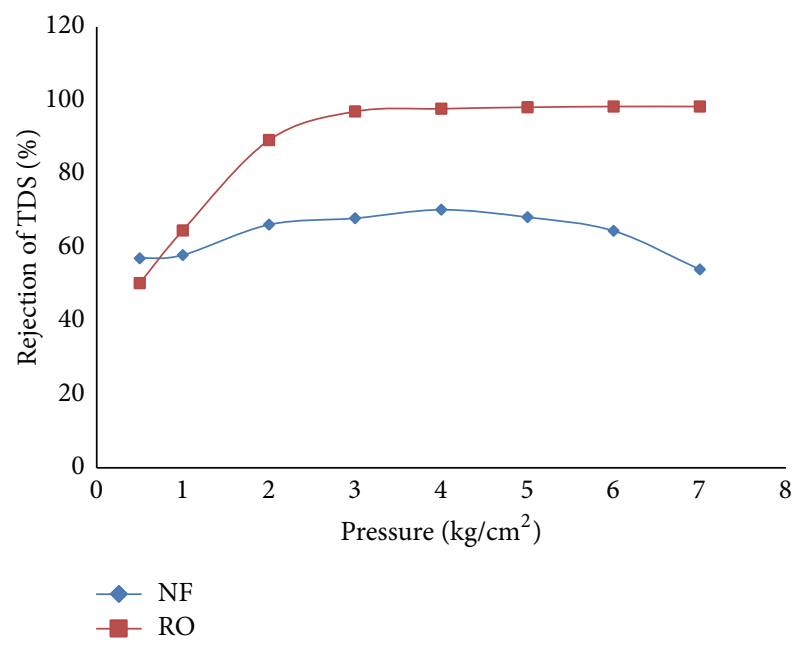

FIgURE 6: Comparing \% rejection of TDS as a function of pressure between $\mathrm{NF}$ and RO.

organic compound using NF membrane. These studies indicate greater potential of NF membranes compared to several established treatments. Higher retention of contaminants was achieved. Generally the TOC reduction would be merely 5$10 \%$ for conventional treatments [16], but NF has given higher reduction of $60 \%$. This will lead to decrease in toxic chemicals present in the water and hence their consumption. Similarly RO treatment has yielded $63 \%$ TOC reduction.

3.3. TDS and Chlorides Rejection by Membrane. This removal of organic compound continued collectively with removal of inorganic ions (Figure 6). It can be seen from the figure that the rejection of TDS increases with increase in applied pressure. The increase was dominating till 3 bars, because the ion transport due to convection becomes significant compared to diffusion. Thereafter the increase in rejection was negligible, reaching a limiting value at 6 bars. The maximum rejection of TDS by NF is found to be $70 \%$ from the feed water. TDS dropped from $451 \mathrm{mg} / \mathrm{L}$ to $135 \mathrm{mg} / \mathrm{L}$. It makes NF highly suitable as potable water. On the other hand, quick elimination of TDS was observed for RO treatment, as

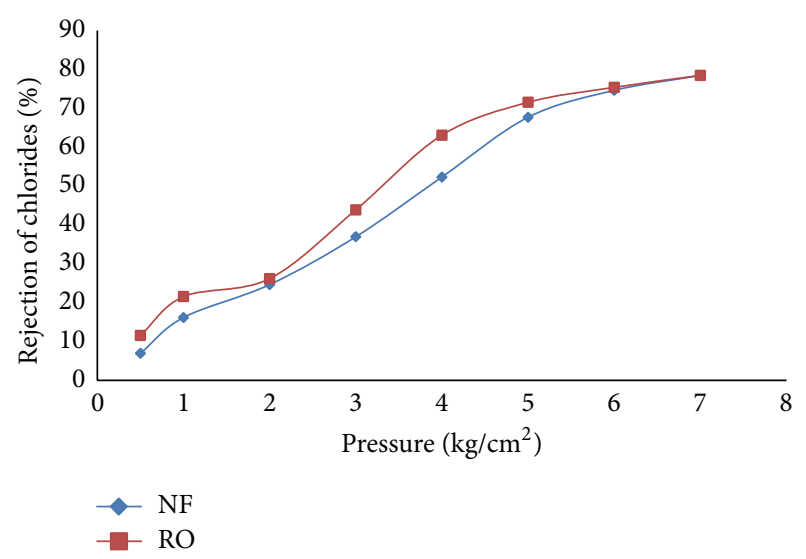

Figure 7: Comparing \% rejection of chloride as a function of pressure between NF and RO.

the applied pressure increasing the \% rejection of TDS is increased gradually and reached the steady value of $98 \%$ rejection at 2 bars and it has remained the same although the pressure has increased. TDS reduced to as low as $14.3 \mathrm{mg} / \mathrm{L}$ at the limiting value of 7 bars. Although the RO process has given higher TDS reduction, such high reduction is undesirable to use as potable water. A low TDS will force the salts in the body to come out of tissues and as the water comes out through kidneys, some of these minerals are lost to the body. Considering these aspects, NF performance is deemed to be optimal and acceptable as potable water. The chloride removal data is shown in Figure 7. It can be seen that $80 \%$ rejection was observed for $\mathrm{RO}$ while $72 \%$ rejection was observed for NF for the limiting pressure of 7 bars.

3.4. Nitrates, Sulphates, and Phosphates Rejection by Membrane. The nitrates, sulphates, and phosphates presence in surface water is one of the main problems related with the quality of the water. Excess nitrates and phosphates can accelerate eutrophication rendering surface water polluted and undrinkable. Figure 7 presents the effectiveness of NF in removing the nitrates, sulphates, and phosphates from the surface water. It can be seen that sulphate ion is maximally rejected compared to phosphates and nitrates. This could be because of higher hydration energy and charge associated with sulphate ions (Figure 8).

3.5. Power Consumption. Figure 9 compares the energy consumption of RO and NF filtration. It can be noted that $21 \mathrm{Lmh}$ can be obtained at $200 \mathrm{~W}$ in case of NF but the same flux was obtained at $448 \mathrm{~W}$ in case of RO system. Besides, the electricity consumption is always on the higher side for $\mathrm{RO}$ membrane [17]. Hence the electrical power consumption in case of RO system is more than two times that of NF for the same flow rate. Thus NF not only gives potable water but also gives in an energy efficient way.

\section{Conclusions}

It was found that nanofiltration is effective in providing required TDS from the surface water (Cauvery river water) 


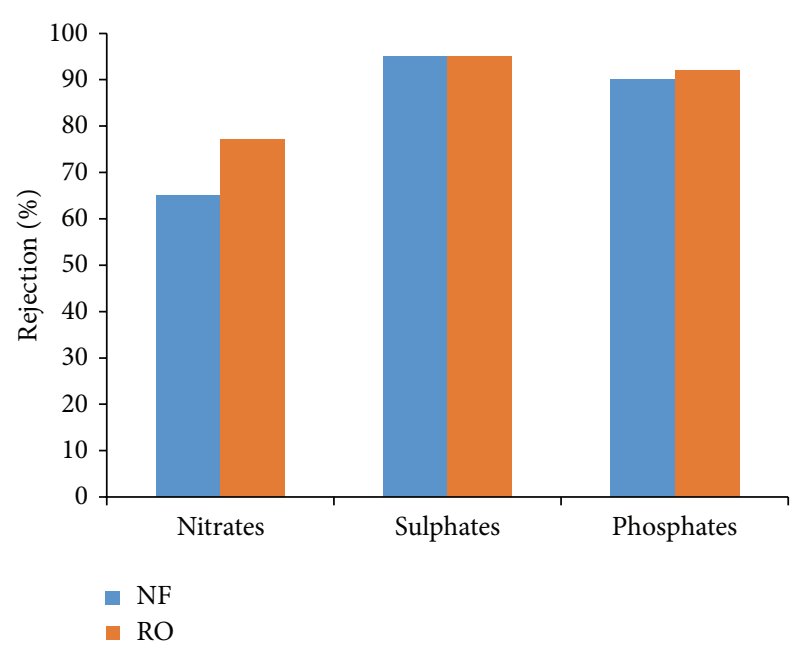

FIGURE 8: \% rejection of nitrates, sulphates, and phosphates using $\mathrm{NF}$ and $\mathrm{RO}$.

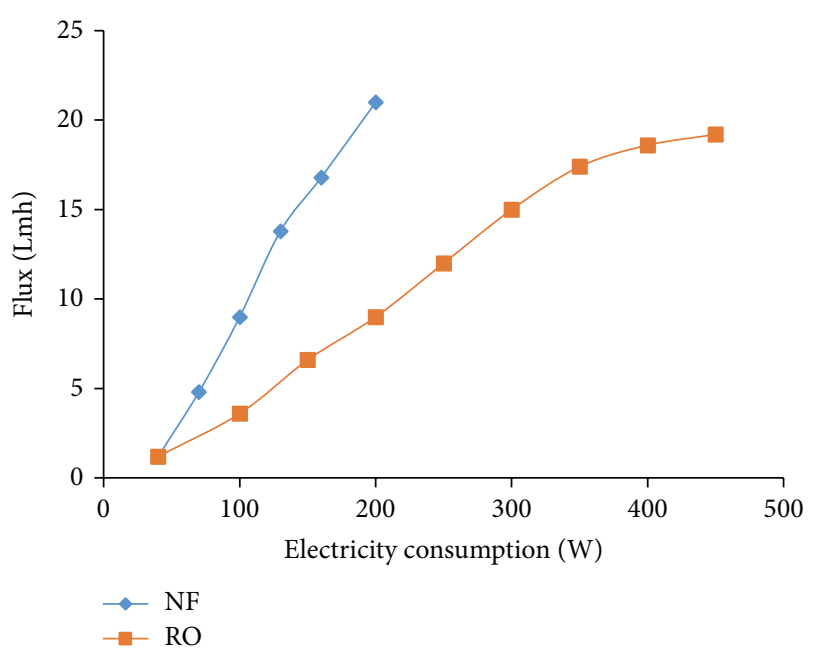

FIGURE 9: Comparison of RO and NF electricity consumption for same permeate flux.

and makes it as potable water. The experimental results have shown that increasing the applied pressure resulted in an increase of TDS rejection from surface water. Although it seems to be, the NF cannot reduce the total TDS but the fact is that it is only more effective as far as potable water is concerned since in potable water it is a must that some minerals should be dissolved in water as per the standards of WHO; otherwise it is harmful for health. A reduction in TDS from $451 \mathrm{mg} / \mathrm{L}$ to $135 \mathrm{mg} / \mathrm{L}$ was observed during NF process. So in an economic and health perspective to produce potable water the NF is the best. Additionally electricity consumption was found to be low in case of NF, making it apposite for potable water. In fact, in future, we would like to come up with an operation of nanofiltration using renewable energy, thus further reducing the energy consumption.

\section{Conflict of Interests}

The authors declare that there is no conflict of interests regarding the publication of this paper.

\section{Acknowledgment}

The authors thank MHRD (Ministry of Human Resource Development), Government of India, for providing financial support through their institute, National Institute of Technology, Trichy (in the form of seed money for research scholars).

\section{References}

[1] M. L. Fornasero, R. N. Marenchino, and C. L. Pagliero, "Deacidification of soybean oil combining solvent extraction and membrane technology," Advances in Materials Science and Engineering, vol. 2013, Article ID 646343, 5 pages, 2013.

[2] S. Sobana and R. C. Panda, "Identification, modelling, and control of continuous reverse osmosis desalination system: a review," Separation Science and Technology, vol. 46, no. 4, pp. 551-560, 2011.

[3] N. A. Sani, W. J. Lau, and A. F. Ismail, "Polyphenylsulfone-based solvent resistant nanofiltration (SRNF) membrane incorporated with copper-1,3,5-benzenetricarboxylate (Cu-BTC) nanoparticles for methanol separation," RSC Advances, vol. 5, no. 17, pp. 13000-13010, 2015.

[4] European Union, "Council Directive 98/83/EC of 3 November 1998 on the quality of water intended for human consumption," Official Journal of the European Communities, vol. L330, pp. 32$54,1998$.

[5] P. Garzon and M. J. Eisenberg, "Variation in the mineral content of commercially available bottled waters: implications for health and disease," The American Journal of Medicine, vol. 105, no. 2, pp. 125-130, 1998.

[6] B. van der Bruggen and C. Vandecasteele, "Removal of pollutants from surface water and groundwater by nanofiltration: overview of possible applications in the drinking water industry," Environmental Pollution, vol. 122, no. 3, pp. 435-445, 2003.

[7] M. A. Shannon, P. W. Bohn, M. Elimelech, J. G. Georgiadis, B. J. Marĩas, and A. M. Mayes, "Science and technology for water purification in the coming decades," Nature, vol. 452, no. 7185, pp. 301-310, 2008.

[8] M. A. Montgomery and M. Elimelech, "Water and sanitation in developing countries: including health in the equation," Environmental Science and Technology, vol. 41, no. 1, pp. 17-24, 2007.

[9] A. Orecki, M. Tomaszewska, K. Karakulski, and A. W. Morawski, "Surface water treatment by the nanofiltration method," Desalination, vol. 162, no. 1-3, pp. 47-54, 2004.

[10] Raman, N. Cheryan, and N. Rajagopalan, "Consider nanofiltration for membrane separation," Chemical Engineering Progress, vol. 90, pp. 68-74, 1994.

[11] P. Eriksson, "Nanofiltration extends the range of membrane filtration," Environmental Progress, vol. 7, no. 1, pp. 58-61, 1988.

[12] R. S. Harisha, K. M. Hosamani, R. S. Keri, S. K. Nataraj, and T. M. Aminabhavi, "Arsenic removal from drinking water using thin film composite nanofiltration membrane," Desalination, vol. 252, no. 1-3, pp. 75-80, 2010.

[13] R. Rautenbach and R. Albrecht, Membrane Processes, Wiley, Chichester, UK, 1989. 
[14] S. Sridhar, A. Kale, and A. A. Khan, "Reverse osmosis of edible vegetable oil industry effluent," Journal of Membrane Science, vol. 205, no. 1-2, pp. 83-90, 2002.

[15] M. Pizzichini, C. Russo, and C. D. Di Meo, "Purification of pulp and paper wastewater, with membrane technology, for water reuse in a closed loop," Desalination, vol. 178, no. 1-3, pp. 351359, 2005.

[16] R. J. Petersen, "Composite reverse osmosis and nanofiltration membranes," Journal of Membrane Science, vol. 83, no. 1, pp. 81150, 1993.

[17] I. C. Escobar, S. Hong, and A. Randall, "Removal of assailable and biodegradable dissolved organic carbon by reverse osmosis and nanofiltration membranes," Journal of Membrane Science, vol. 175, pp. 1-17, 2000. 

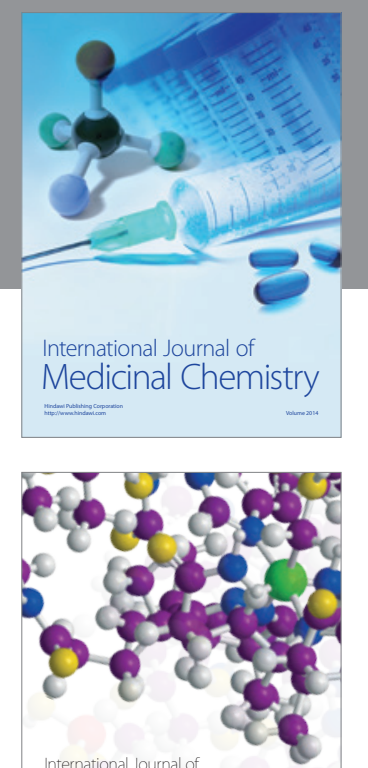

\section{Carbohydrate} Chemistry

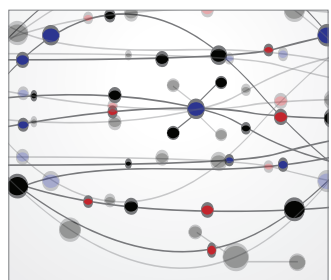

The Scientific World Journal
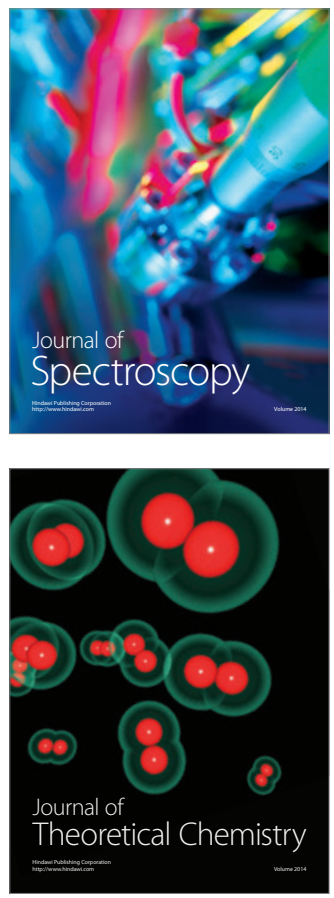
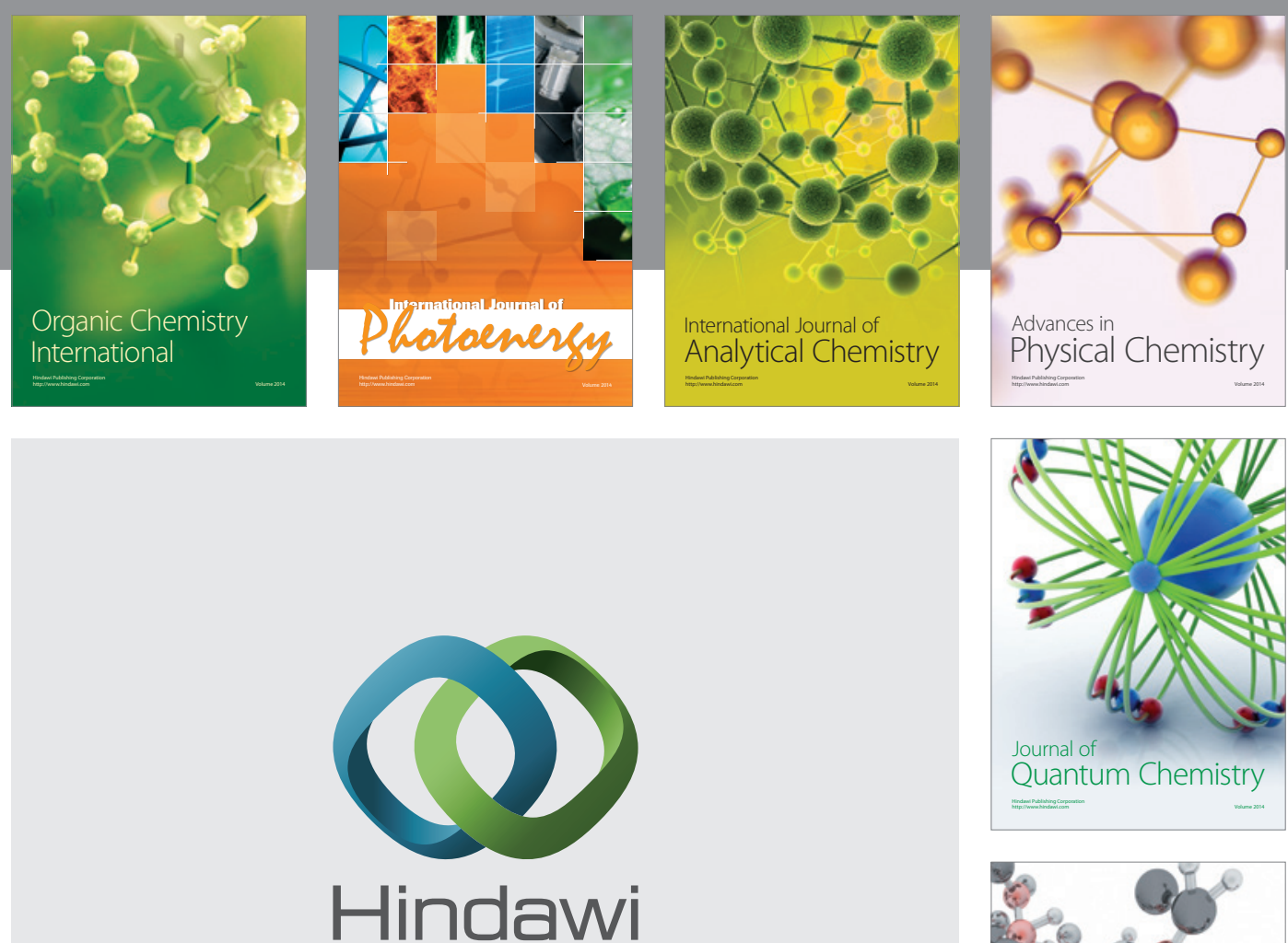

Submit your manuscripts at

http://www.hindawi.com

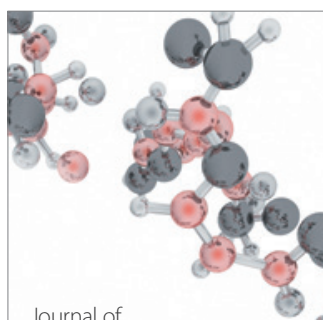

Analytical Methods

in Chemistry

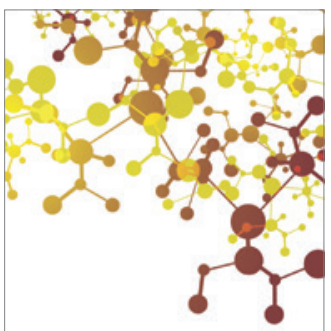

Journal of

Applied Chemistry

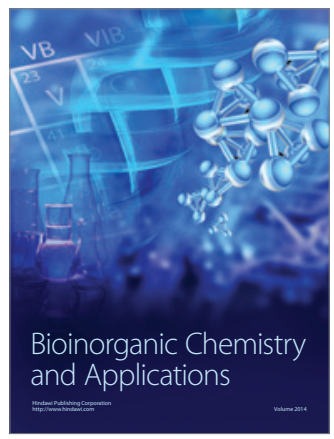

Inorganic Chemistry
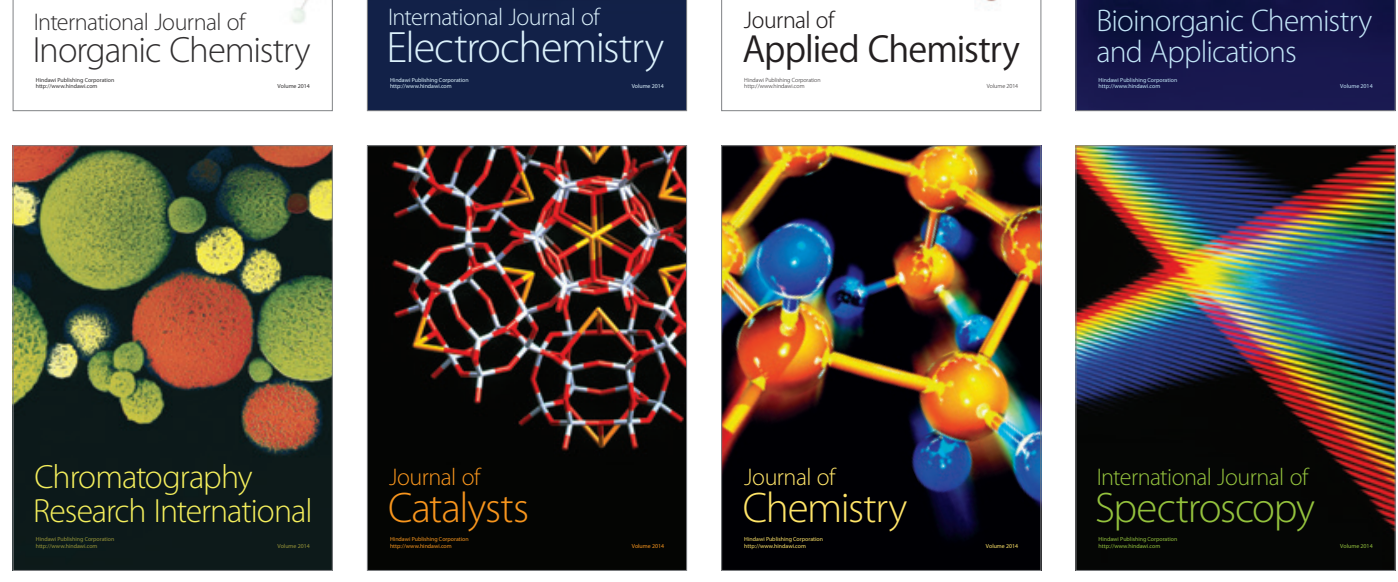